Marquette University

e-Publications@Marquette

Mechanical Engineering Faculty Research and

Publications

Mechanical Engineering, Department of

6-15-2019

\title{
Crack Propagation and Microstructural Transformation on The Friction Surface of a High-Speed Railway Brake Disc
}

\author{
Zhizhong Wang \\ Beijing Jiaotong University \\ Jianmin Han \\ Beijing Jiaotong University \\ Joseph P. Domblesky \\ Marquette University, joseph.domblesky@marquette.edu \\ Zhiqiang Li \\ Beijing Jiaotong University \\ Xinguang Fan \\ Beijing Jiaotong University
}

See next page for additional authors

Follow this and additional works at: https://epublications.marquette.edu/mechengin_fac

Part of the Mechanical Engineering Commons

\section{Recommended Citation}

Wang, Zhizhong; Han, Jianmin; Domblesky, Joseph P.; Li, Zhiqiang; Fan, Xinguang; and Liu, Xiaolong, "Crack Propagation and Microstructural Transformation on The Friction Surface of a High-Speed Railway Brake Disc" (2019). Mechanical Engineering Faculty Research and Publications. 245.

https://epublications.marquette.edu/mechengin_fac/245 


\section{Authors}

Zhizhong Wang, Jianmin Han, Joseph P. Domblesky, Zhiqiang Li, Xinguang Fan, and Xiaolong Liu

This article is available at e-Publications@Marquette: https://epublications.marquette.edu/mechengin_fac/245 
Marquette University

e-Publications@Marquette

\section{Mechanical Engineering Faculty Research and Publications/College of} Engineering

This paper is NOT THE PUBLISHED VERSION; but the author's final, peer-reviewed manuscript. The published version may be accessed by following the link in th citation below.

Wear, Vol. 428-429 (June 15, 2019): 45-54. DOI. This article is (C) Elsevier and permission has been granted for this version to appear in e-Publications@Marquette. Elsevier does not grant permission for this article to be further copied/distributed or hosted elsewhere without the express permission from Elsevier.

\section{Crack Propagation and Microstructural Transformation on The Friction Surface of a High-Speed Railway Brake Disc}

\section{Zhizhong Wang}

School of Mechanical Electronic \& Control Engineering, Beijing Jiaotong University, Beijing 100044, China

Jianmin Han

School of Mechanical Electronic \& Control Engineering, Beijing Jiaotong University, Beijing 100044, China Joseph P. Domblesky

Mechanical Engineering Department, Marquette University, Milwaukee, WI

Zhiqiang Li

School of Mechanical Electronic \& Control Engineering, Beijing Jiaotong University, Beijing 100044, China 


\title{
Xinguang Fan
}

\section{School of Mechanical Electronic \& Control Engineering, Beijing Jiaotong University, Beijing 100044, China}

\section{Xiaolong Liu}

\author{
School of Mechanical Electronic \& Control Engineering, Beijing Jiaotong University, Beijing 100044, \\ China
}

\begin{abstract}
While brake disc wear represents a significant problem in high-speed rail systems, the progressive development of fatigue cracks during successive braking cycles also plays a great role in braking integrity. The modified microstructure consisting of a white etching layer (WEL) containing nanosized ferrite was observed on the friction surface of worn brake discs. In order to analyze how sequential thermal and mechanical stress affected crack propagation and microstructure evolution in brake discs, successive braking cycles were simulated on a full-scale braking bench test rig. Crack initiation and propagation mechanisms were proposed based on the experimental results, i.e., (i) occurrence of heat checking caused by heating and cooling transients during braking; (ii) heat checking increasing the roughness of the friction surface which in turn caused a local stress concentration and (iii) localized friction stress and thermal stress driving the heat checking to propagate and coalesce with the radial main crack. Analysis of the thermal-mechanical conditions that exist at the friction surface during braking indicates that WEL formation can be attributed to severe plastic deformation caused by the repeated friction between the disc and pads. Mechanical testing also indicated that WEL formation is not detrimental to brake disc integrity.
\end{abstract}

\section{Keywords}

Brake disc, Heat checking, Radial main crack, White etching layer, Nanosized ferrite

\section{Introduction}

Increased running speed and axle loads represent an on-going trend in the operation of modern high-speed rail systems, and pose greater demands not only on structural performance, but also on the integrity of key friction pairs such as the wheel/rail and disc/pad systems [1], [2], [3], [4]. The development of shear cracks and microstructural alterations adjacent to the wheel/rail contact surface have drawn significant research interest over the past two decades. It is believed that contact force induces structural modifications, which ultimately leads to microcrackformation and spalling in the wheel/rail system [5], [6]. In comparison, crack behaviour and microstructure transformation on railway brake disc/pad friction pairs have not been widely studied and less is known about the underlying causes.

Due to the increasingly severe operating conditions, thermal damagesincluding hot spots, heat checking and radial main crack, as shown in Fig. 1, frequently form on the friction surface of brake discs [7]. The formation of hot spots is attributed to the local high temperature during braking, and the thermal stress caused by heating and cooling transients during service is responsible for the formation of these thermal cracks [8], [9], [10]. As shown in Fig. 1, alternate occurrence of the heat checking and radial main crack are presented on the fiction surface, indicating a kind of competition in these two crack types. Experimental and numerical techniques have been employed to investigate these two crack behaviours. Radial main cracks appear on the surface of service discs which operate at $300 \mathrm{~km} / \mathrm{h}$, while only heat checking formed after repeated emergency braking tests at $200 \mathrm{~km} / \mathrm{h}$ [7], [11]. The propagation of a surface crack in the center of a hot spot was simulated by finite element method at a braking speed of $400 \mathrm{~km} / \mathrm{h}$, and the fatigue crack propagation curve between the crack 
length and emergency braking cycles was obtained, indicating the propagation of the radial main crack [12], [13]. Thus, with the increase of the braking speed from $200 \mathrm{~km}$ to $400 \mathrm{~km}$ the surface cracks propagation varied.

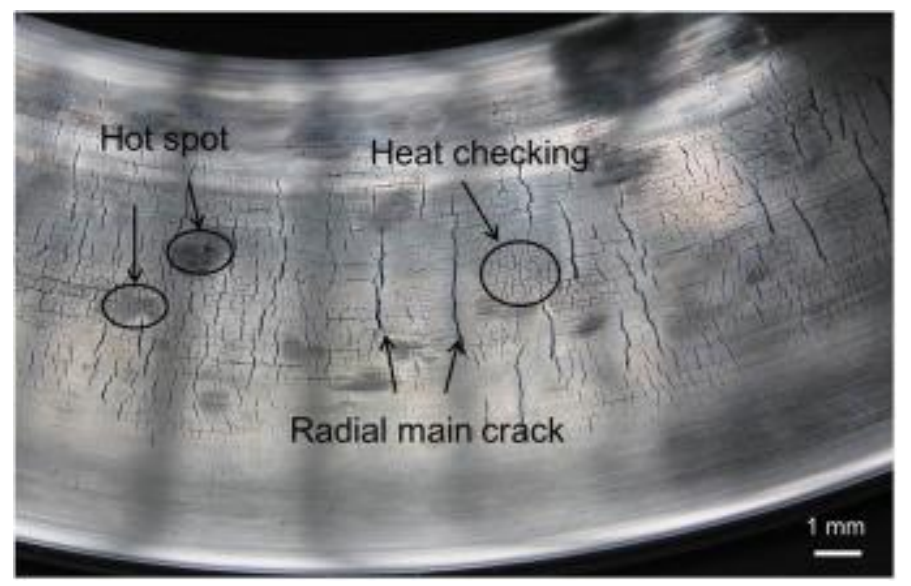

Fig. 1. Thermal damages including radial main crack, heat checking and hot spot on friction surface [7].

Gradual surface microstructure modification has been observed in rails and wheels by optical microscopy, which displays a white and 10- to 100-mm-thick layer called a white etching layer (WEL) [14], [15]. In general, the microstructure modification associated with WEL involves a combination of phase transformation and grain refinement with grains varying from tens to hundreds of nanometers [16], [17]. The reported WELs are composed of ferrites [18], martensite [19], and coexistence of various phases of severely deformed pearlite, nanosized martensite, austenite and carbides [6] for different initial microstructure and loading conditions. WEL formation mechanisms have been hypothesized to be either thermally induced through phase transformations (T-WL) or mechanically induced through severe plastic deformation (M-WL) [20]. Meanwhile, in what way the WELs change the properties is not clear in the literature [21], [22]. Both positive and negative effects have been described, and this warrants further investigation. This raises an interesting issue: as a key friction pair, is there WEL on the friction surface of brake disc? If yes, what is the composition of the WEL and the influence of the WEL on the mechanical properties of the friction surface?

In this paper, crack propagation and microstructural transformation on the friction surface of high-speed railway brake discs were investigated. For the investigation, two brake discs on a wheel were taken from service and the presence of existing heat checking and radial main cracks on the friction surfaces were observed and recorded. A series of braking tests were then conducted using a full-scale braking bench to study how heat checking and radial main cracks propagated during braking cycles. WELs were observed on the friction surface by optical microscopy and electron back-scattered diffraction (EBSD) and the corresponding formation mechanism was identified. Mechanical testing was also conducted on the specimens containing a WEL to ascertain the effects on mechanical properties.

\section{Experiments details}

\subsection{Brake disc and pad materials}

Two full size brake discs and a set of pads were used as shown in Fig. 2. Since crack propagation and microstructural transformation are the main concern of this paper, two used brake discs (referred to as A and B) with pre-existing surface cracks were employed. Each disc was $720 \mathrm{~mm}$ in diameter and weighed approximately $72 \mathrm{~kg}$. The brake discs were made from a forged medium carbon low alloy steel (AISI 4340 equivalent) with a chemical composition (mass percentage) as shown in Table 1 . The 
original microstructure of the material taken from a new brake disc is presented in Fig. 3 and consists primarily of tempered sorbite (mixture of ferrite and carbide phases). The failure of brake discs in high-speed trains during service is determined by the length of radial main crack (Fig. 2b), i.e., any radial main crack exceeds a certain length according to the related standard, the disc is considered to have failed. A brake disc with cracks in the actual train is acceptable, but monitoring of the crack propagation is crucial for the safety of the train. A total of twenty four radial main cracks distributed uniformly on the friction surfaces of disc $A$ and $B$ were chosen and identified as A1-A12 and B1-B12 respectively. In addition, the pads are made from copper based powder metallurgy.

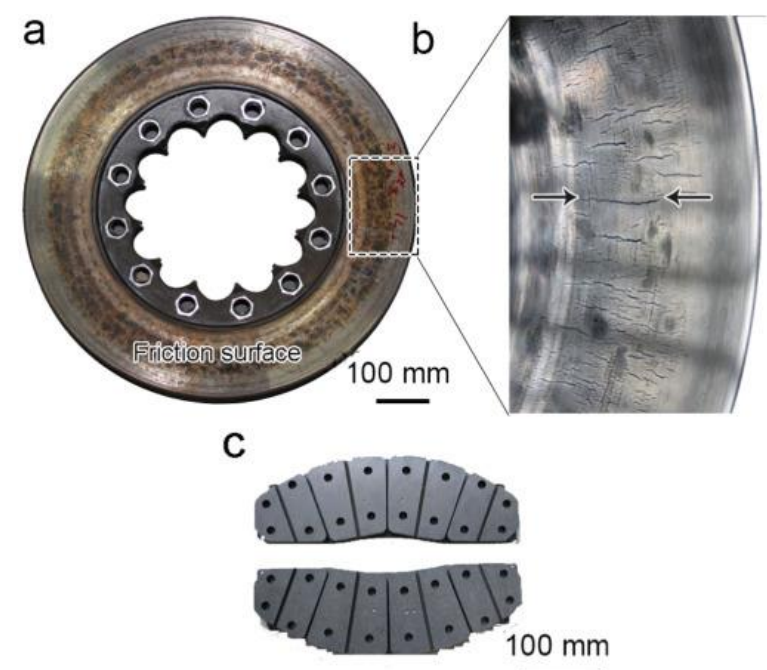

Fig. 2. Photograph showing (a) brake disc $A$, (b) typical radial main crack and (c) corresponding set of brake pads used in the study.

Table 1. Nominal chemical compositions of the brake disc (mass percentage).

\begin{tabular}{|l|l|l|l|l|l|l|}
\hline $\mathbf{C}$ & $\mathbf{C r}$ & $\mathbf{N i}$ & $\mathbf{M o}$ & $\mathbf{S i}$ & $\mathbf{M n}$ & $\mathbf{F e}$ \\
\hline $\mathbf{0 . 3 1}$ & 1.1 & 1.8 & 0.5 & 0.25 & 0.75 & Balance \\
\hline
\end{tabular}

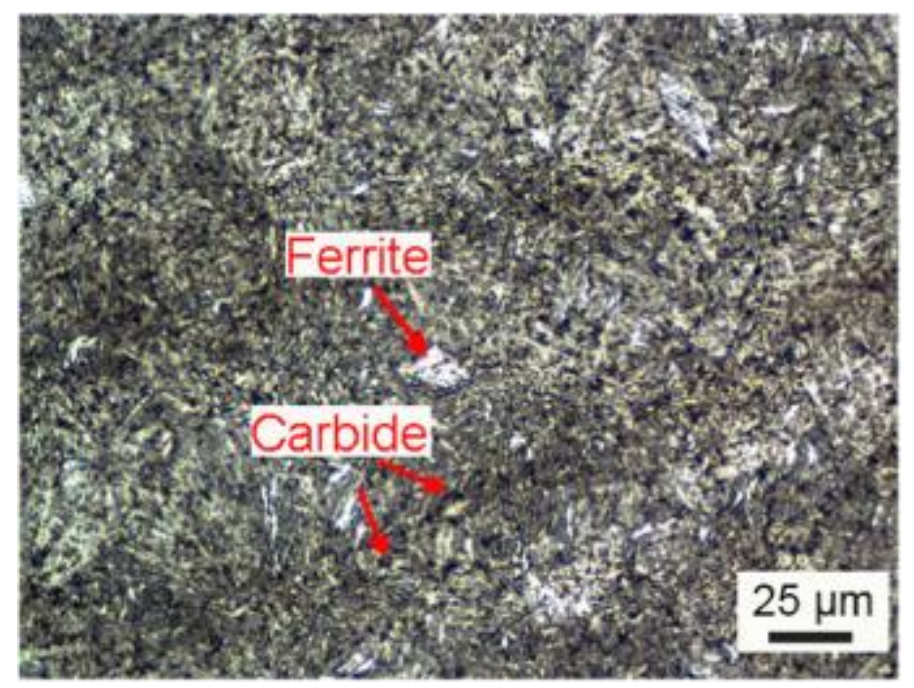

Fig. 3. Microstructure of the material from a new brake disc (Carbide: Dark particle, Ferrite: light color lamella). 


\subsection{Experimental procedure}

It was of great interest to characterize the damage evolution on the friction surface during service. The damage evolution on the friction surface as a function of the number of braking cycles was investigated based on the examination of brake discs from an actual train during scheduled maintenance work. Fig. 4 presents sequence of damage evolution on the friction surface of the brake disc during service. In the first one thousand braking cycles, only superficial scrape marks were observed on the friction surface of the brake disc. After brake disc had been subjected to $10^{3}-10^{4}$ braking cycles, heat checking appeared on the friction surface. After $10^{4}$ times braking cycles, radial main cracks began to appear. The sequential occurrence of heat checking and radial main crack is related to the corresponding formation mechanism, and will be discussed later.

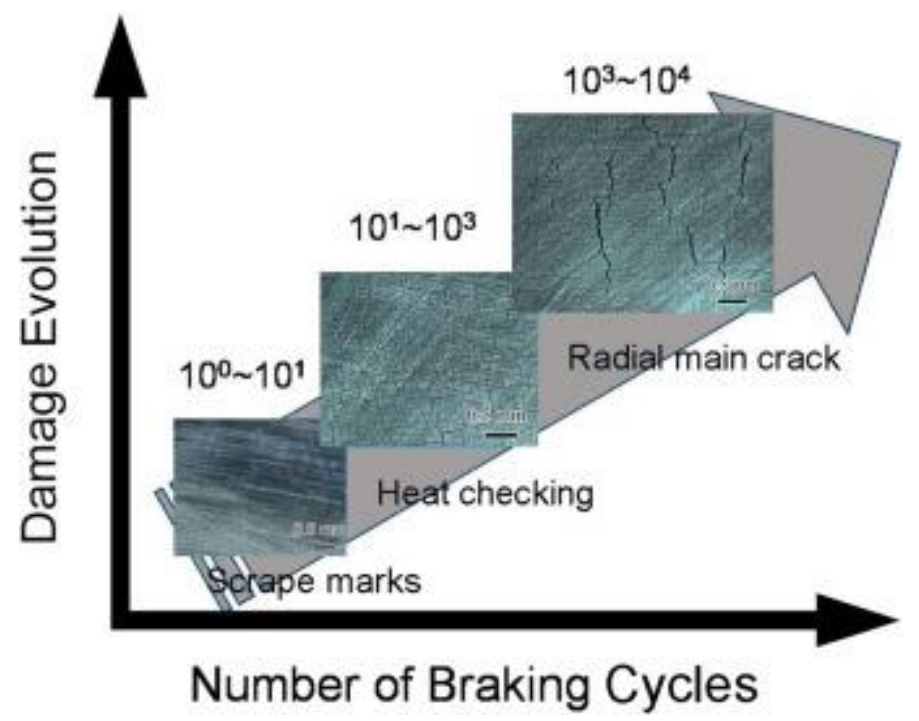

Fig. 4. Sequence of damage evolution on the friction surface of the brake disc during service.

To study crack growth and microstructure changes resulting from successive braking cycles, the discs and pads were subjected to a total of 1056 braking cycles using a full-scale braking bench test rig (RENK Test System $\mathrm{GmbH}$ ) which is shown in Fig. 5. The test rig consists of an electric motor and flywheel which drive a train axle equipped with a hydraulic braking system. The maximum wheel velocity that can be achieved by the bench is $420 \mathrm{~km} / \mathrm{h}$ which is well in excess of the operating speed used during normal high speed rail travel. Prior to testing, a wheel with the test discs was mounted on the axle. Grinding-in is then performed to ensure full contact between the disc and pad. The speed for grinding-in is $70 \mathrm{~km} / \mathrm{h}$, and the thrust force to the pads is $35 \mathrm{kN}$. After a period of grinding-in, the pads were observed to measure the contact area. If the contact area is more than $85 \%$, the grinding-in process finishes. If not, the grinding-in is continued. Then, the axle-wheel system is then driven to the target testing speed of $300 \mathrm{~km} / \mathrm{h}$ and maintained at this value for $2 \mathrm{~min}$. Due to no radial main crack propagation occurring at the braking speed of $200 \mathrm{~km} / \mathrm{h}$ [10], the braking speed of $300 \mathrm{~km} / \mathrm{h}$ in these tests was chosen. The axle load for one disc is $8 \mathrm{kN}$, and the amount of energy dissipated in the emergence braking was calculated to be about $28 \mathrm{MJ}$. Braking action is then accomplished by a hydraulic actuator which applied a $19 \mathrm{kN}$ force to the pads and then increased to $24 \mathrm{kN}$ until a complete stop. This sequence is consistent with the emergency braking procedure used on actual train. In service braking, first the electro-dynamic braking is applied, and then the disc braking at a small speed, while the disc braking is launched at the beginning of emergency braking. Although the emergency braking hardly ever happens in the service, the crack propagation on the friction surface of the disc in the extreme condition of emergency braking has scientific significance and reference value for understanding the reliability of a disc. The temperature on the friction surface of the disc $A$ during braking was measured using a Fotric infrared system. At the completion of about one hundred and fifty tests, the friction surfaces were polished using 400\#, 800\# and 1200\# abrasive papers and then photographed 
using a digital camera. The reason for polishing is that after braking the friction surface was covered by a third body consisting of oxide and abrasive dust which impede the observation of cracks. The lengths of the fatigue cracks were then measured from the photographs in the course of the tests.

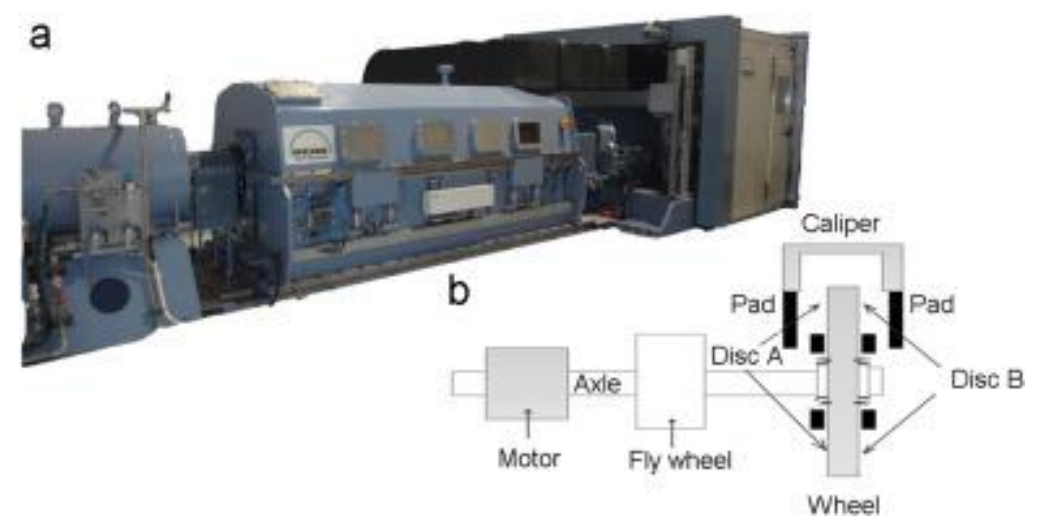

Fig. 5. Photograph and corresponding schematic showing (a) full-scale braking bench, and (b) diagram of the test set-up.

After bench testing was completed, samples were cut from friction surface of the brake disc A using a wireelectrode discharge machine to enable microstructure characterization and mechanical testing to be performed. The Vickers hardness of the matrix and the friction surface were first measured using a FUTURE-TECH ASR900 microhardnesstester. The specimens were then polished and etched using Nital reagent to reveal the microstructure on the friction surface and matrix by an OLYMPUS BX51 optical microscope and EBSD using $100 \mathrm{~nm}$ step size. Optical microscopy was also used to observe the cracks on the friction surface. It is worth noting that the microstructure and microhardness analysis were conducted at a location far from the cracks, and no evident difference of microstructure and microhardness was presented between the place close and far away from the cracks. A 3 Dimensional Phase Shift MicroXAM was employed to measure the roughness of the chosen location on friction surface. Tensile specimens, with a gauge length of $15 \mathrm{~mm}$ and width of $4 \mathrm{~mm}$, were cut from the friction surface of a brake disc. For investigating the effects of the WEL on the mechanical properties of friction surface, a series of test specimens were made having thicknesses of $0.05 \mathrm{~mm}, 0.1 \mathrm{~mm}, 0.21 \mathrm{~mm}$, $0.35 \mathrm{~mm}$, and $0.5 \mathrm{~mm}$. All specimens were mechanically polished prior to tensile testing in order to remove any surface irregularities and to permit a more accurate determination of the cross-sectional area.

Uniaxial tensile tests were carried out at a constant strain rate of $5 \times 10^{-4} \mathrm{~s}^{-1}$ using an MTS Landmark testing machine.

\section{Results and discussion}

\subsection{Crack propagation on the friction surface}

Fig. 6a shows a representative distribution of heat checking and radial main cracks on the friction surface obtained by optical microscopy. It can be seen that a radial main crack is clearly evident and surrounded by a network of heat checking. The heat checking demonstrates the characteristic reticulate pattern in the circumferential and radial directions. The crack tip of the radial main crack joined with the heat checking. Fig. $6 \mathrm{~b}$ shows a cross-section profile of heat checking and a radial main crack. It is worth noting that subsurface cracking was also observed in the cross-section profile. The subsurface cracks are perpendicular to the friction surface and locate at the depth of $400 \mu \mathrm{m}$ from the surface. This crack type is prevalent in the fatigue of railway wheels, but rarely reported for the case of brake discs. Since the surface cracks including heat checking and radial main crack are the main cause for the failure of brake disc, the investigation of subsurface crack will be conducted in future. Both cracks are perpendicular to the friction surface. It is indicated that both cracks are Mode I cracks which is different from the shear crack in the WEL of wheels [14]. The depth of radial main crack is larger than 
that of heat checking. Measurements confirmed this and showed that crack depth of the heat checking ranges from $0.1 \mathrm{~mm}$ to $0.45 \mathrm{~mm}$ with an average value of $0.18 \pm 0.1 \mathrm{~mm}$. In comparison, the depth of the radial main cracks varied from $0.5 \mathrm{~mm}$ to $2.0 \mathrm{~mm}$ with an average value of $1.2 \pm 0.5 \mathrm{~mm}$ (Fig. 6c).
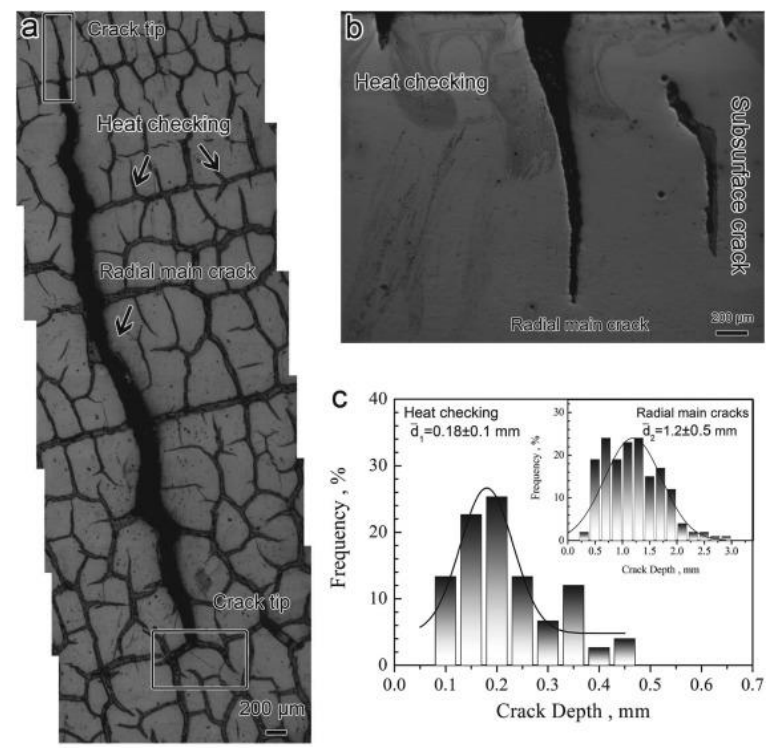

Fig. 6. Photographs showing representative cracks (a) on the friction surface, (b) on the cross-section, and (c) distribution of crack depth.

Fig. 7 presents the crack propagation results where the radial main crack length was measured after increments of about one hundred and fifty braking cycles. As shown in Fig. 7a, the heat checking propagated and coalesced with the radial main crack. In this situation, the heat checking propagated instead of the radial main cracks. Fig. $7 \mathrm{~b}$ presents the length of the radial main crack without propagation. Two thirds of the radial main crack did not propagate in the whole 1056 braking cycles. Fig. 7c presents a summary of radial main crack propagation as a function of braking cycles. The heat checking propagated and coalesced with the radial main cracks, which resulted in the propagation of radial main crack. The corresponding mechanism will be discussed in the next section.

a
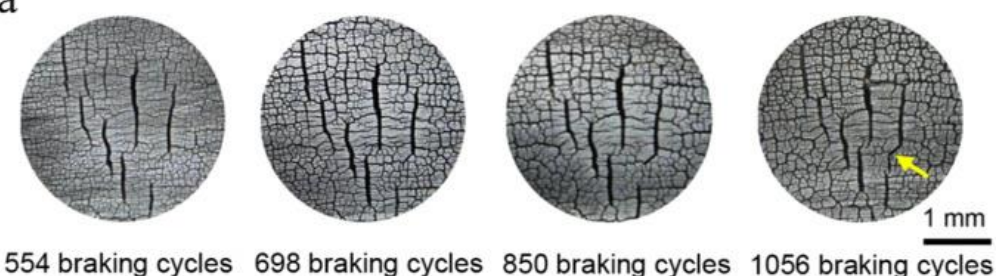

554 braking cycles 698 braking cycles 850 braking cycles 1056 braking cycles
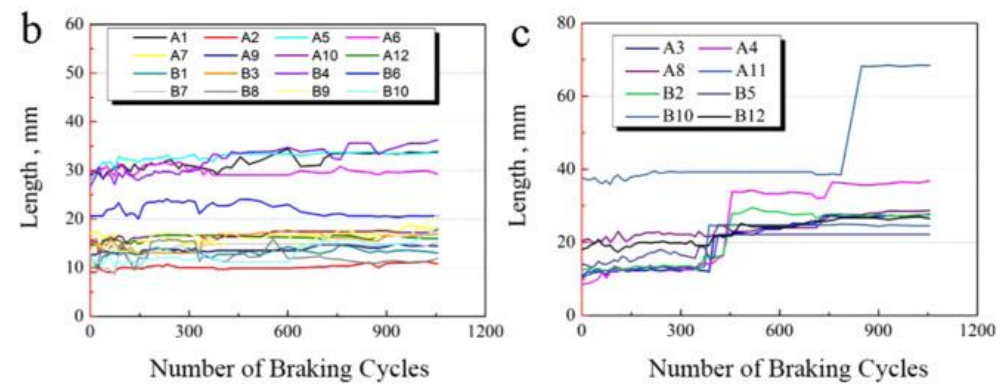

Fig. 7. Radial main crack propagation during full-scale braking tests showing (a) representative crack propagation on the friction surface, (b) summary of radial main cracks without propagation, and (c) summary of radial main cracks with propagation. 
For the railway brake disc/pad friction pairs, the wear in the pad is dominating while that in disc can be ignored. Fig. 8 presents the wear surfaces before braking and after 12 braking cycles. The wear weight loss of the upper pad in Fig. $8 \mathrm{~b}$ is $39.0 \mathrm{~g}$, and that of the lower pad is $36.0 \mathrm{~g}$ after 12 braking cycles. The wear weight loss of the two pads is almost the same. However, the wear rate in each pad is different, i.e. the wear rate in the center of the surface is much severer than that in both sides of the surface. The wear debris filled in the gaps between the blocks which can relieve abrasive wear.
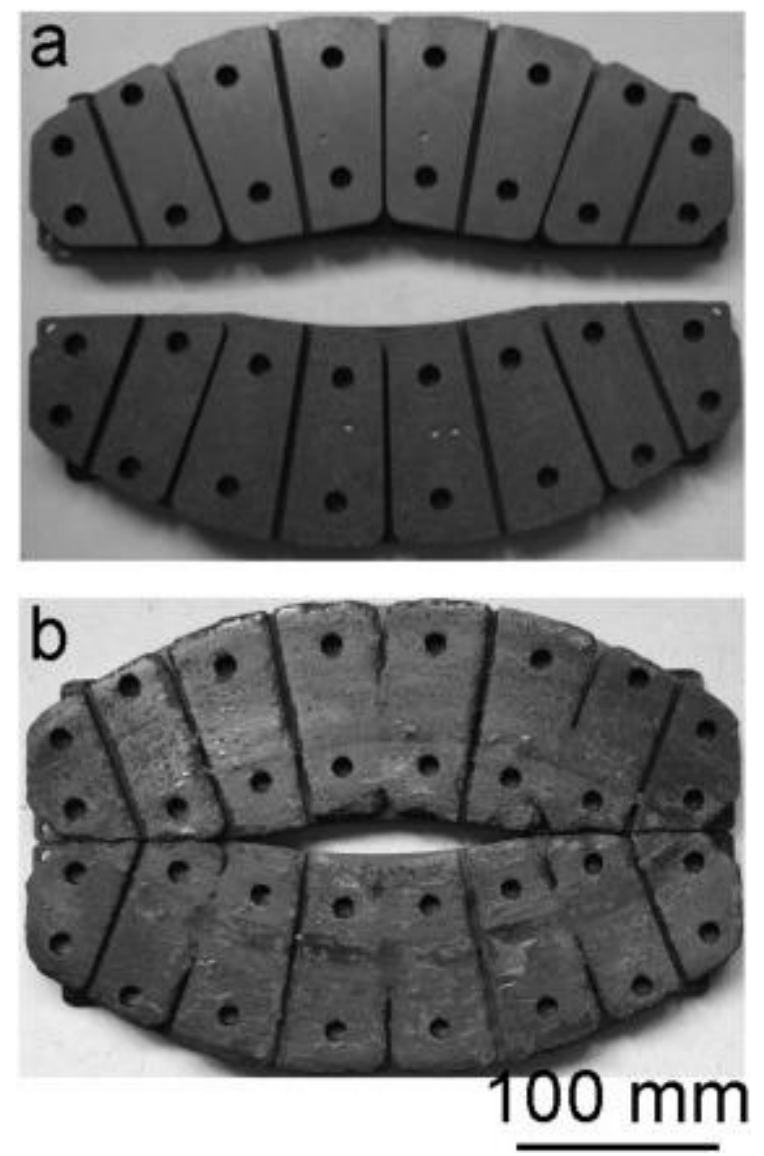

Fig. 8. Comparison of the wear surfaces, (a) before braking and (b) after 12 braking cycles.

\subsection{Crack initiation and propagation mechanism}

As presented in the previous work [7], a significant number of radial main cracks appear on the surface of brake discs which operate at $300 \mathrm{~km} / \mathrm{h}$, while heat checking typically appears after repeated emergency braking (EB) at $200 \mathrm{~km} / \mathrm{h}$. No crack growth was observed on disc surfaces after routine braking at about $50 \mathrm{~km} / \mathrm{h}$. The failure analysis of the brake disc was discussed by evaluating the braking energy for different braking speeds. However, the initiation and propagation for the heat checking and radial main crack were not systematically studied. In this paper, based on the results shown in Figs. 4 and 7, the crack initiation and propagation mechanism on the friction surface can be describe as three stages which include: (i) occurrence of heat checking caused by heating and cooling transients during braking; (ii) heat checking increasing the roughness of the friction surface which in turn causes local stress concentration and (iii) localized friction stress and thermal stress driving the heat checking to propagate and coalesce with the radial main cracks. The details of these three stages are discussed in the following paragraphs. 
The first stage consists of heat checking formation at the beginning of the disc failure. Heat checking is the typical crack type that results from thermal fatigue (Mode I crack) which has been reported in previous literature [7], [9]. As shown in Fig. 6b, the crack direction is nearly vertical to the friction surface, which is different from the reported shear crack in wheels or rails [14]. A brake disc is subjected to a series of heating and cooling transients which is caused by sliding between disc and pad during braking. Either expansive or contractive thermal stress arises when the material is totally or partly constrained. The maximum value of the tensile thermal stress generated on the friction surface calculated by finite element method [10], [11] was about $200 \mathrm{MPa}$ after $300 \mathrm{~km} / \mathrm{h}$ emergency braking and cooling and occurred on the external friction surface. Meanwhile, the brake thrust is $19 \mathrm{kN}$ or $24 \mathrm{kN}$, the area of the pad A is about $175 \mathrm{~cm}^{2}$ and the friction factor can be taken as 0.35 . According to Coulomb's friction law $(f=\mu N / A)$, the friction stress $f$ is about 0.4 or $0.5 \mathrm{MPa}$ which is negligible compared with thermal stress. Thus, given the relatively low level of mechanical loading, this indicates that thermal fatigue of heating and cooling transients is likely responsible for the heat checking initiation on the friction surface of the brake disc (formation of heat checking as shown in Fig. 6) at first.

The occurrence of the heat checking will result in a network of shallow cracks which will tend to increase the roughness of friction surface and further cause the local stress concentration. Fig. 9 presents the 3D morphology and profile of the friction surface with fatigue cracks, indicating more than $30 \mu \mathrm{m}$ height difference. Coulomb's friction law is not applicable for the localization of the friction stress. Quantitative analysis of the friction stress localization will be conducted in a future investigation. The friction stress is in the circumferential directionwhich acts as the driving stress of the heat checking in the radial direction. Combined with the thermal stress, the heat checking in the radial direction grew into the radial main crack, which belongs to the thermal-mechanical fatigue [23], [24].
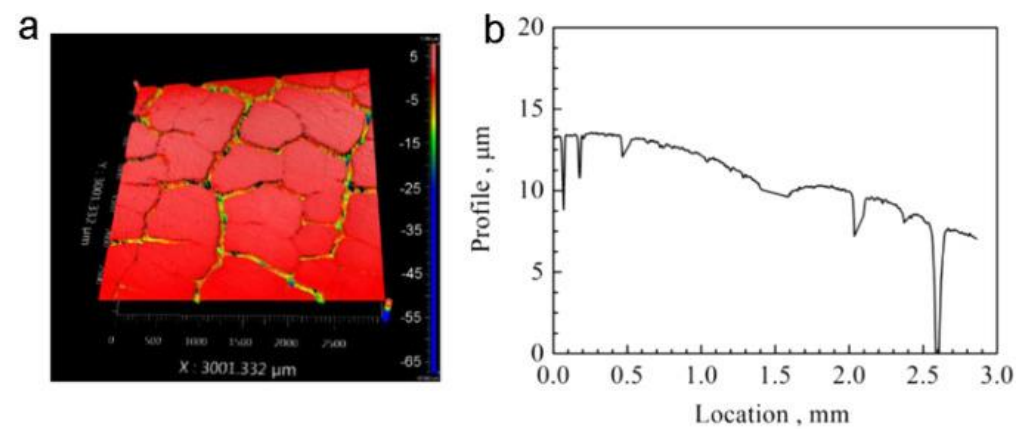

Fig. 9. Surface morphology of the brake disc obtained by phase shift microXAM-3D, (a) 3D morphology, and (b) profile.

In the final stage local friction stress and thermal stress drive the heat checking to propagate and coalesce with the radial main cracks. The thermal stress calculated by finite element method indicates that the distribution of thermal stress decreases in the depth direction [10], [11]. As known, the friction stress tends to decrease with increasing depth from the surface. Fig. 10 presents the schematic of the thermal and friction stress distribution in the depth direction. The depth of the radial main crack is larger than the heat checking as show in Fig. 6 . The thermal-mechanical stress (crack driving force) in the crack tip of heat checking is large, while that of a radial main crack is nearly zero. This is the reason for the crack propagation in this stage. 


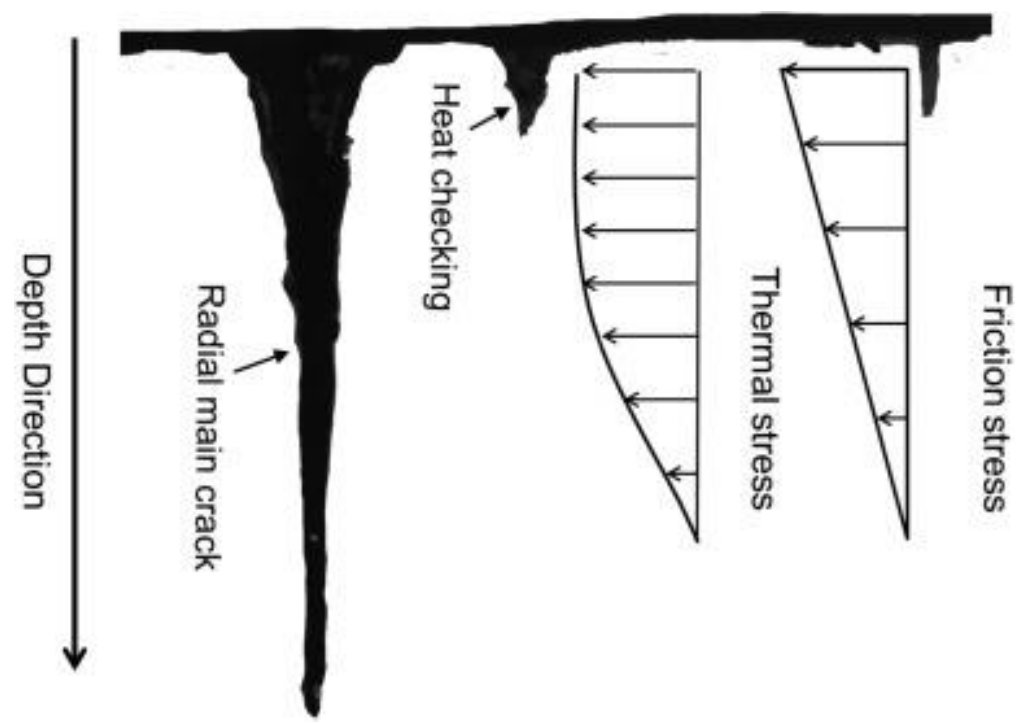

Fig. 10. Schematic showing thermal stress and friction stress distribution perpendicular to the friction surface.

As mentioned above, the failure of the brake disc is that any radial main crack exceeds a certain length. However, based on the discussion the occurrence of heat checking caused the subsequent two stages. Thus, heat checking is the dominant factor in the failure of brake disc. The anti-fatigue design strategy for the brake disc should focus on the suppression of heat checking formation. In general, repetition of heating and cooling transients can result in thermal fatigue of the friction surface. The rate of change in temperature and temperature gradient influences the damage on friction surface. Severe temperature variation may induce plastic deformation in surface layers, which in turn can result in heat checking in $10^{5}$ or less cycles [25], [26]. In general, the braking energy dissipated increased with the increase of the braking speed and axle load, and the temperature variation of brake disc is determined by braking energy dissipated. Therefore, the tendency of modern high-speed rail systems (increased running speed and axle load) will increase the temperature variation on the friction surface and poses challenges on the integrity of the brake disc.

\subsection{WEL on the friction surface}

A hardened layer near the friction surface after a high-energy braking and oxidation of the brake disc steel near the crack edges were observed in the previous work [7]. However, the detail observations and corresponding mechanism were not provided. In this paper, the microstructure and microhardness of the friction surface and subsurface material after braking were characterized in the depth direction. First, Fig. 11a presents the microstructure by optical microscopy. The microstructure in the circumference direction (CD) was similar. However, the microstructure along the depth direction (DD) showed some variation. Three distinct regions can be defined. First, the microstructure near the surface in Fig. 11a is fine and white, and is consistent with that of a WEL [15], indicating that microstructural alteration and grain refinement occurred on and near the surface. Second, the interior microstructure was found to be tempered sorbite which is the same as that of as-received material (Fig. 3). Third, the intermediate layer also has a slight microstructure alteration and grain refinement between the WEL and Matrix. Fig. 11b presents the microstructure in the surface obtained by EBSD. The microstructure in the surface transformed from tempered sorbite into nanosized ferriteaccompanied by decarbonization. Fig. 11c shows the grain size distribution in the surface, indicating the grain size is in the range of 50-550 nm with an average size of $170 \mathrm{~nm}$. The WEL presents the gradient structure with increasing grain size along the depth from nano scale to micro scale. The microstructural transformation and grain refinement is attributed to the friction between the brake disc and padswhich will be discussed later. Fig. 11d presents the tempered sorbite in the interior by EBSD, which is consistent with the results in Fig. 3. 

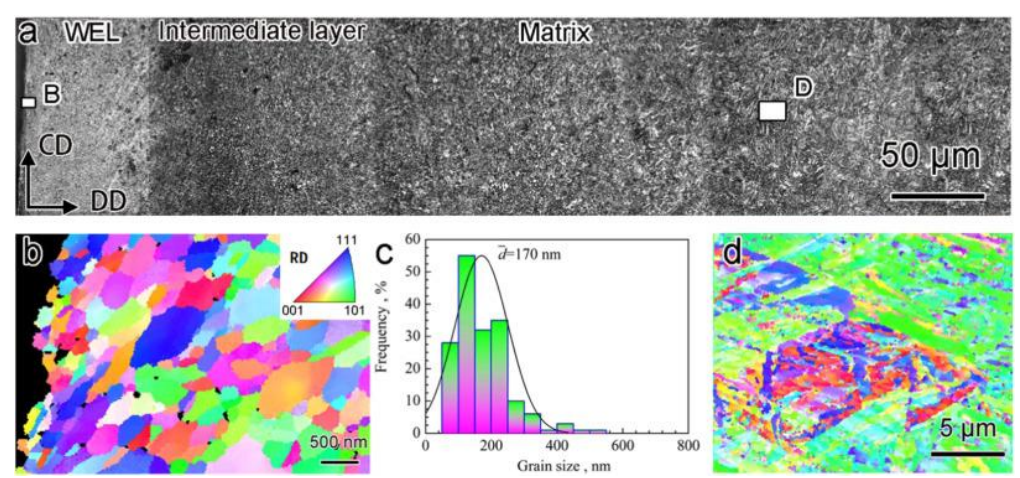

Fig. 11. Microstructure of the friction surface in the depth direction after braking, (a) Microstructure in the depth direction by optical microscopy(CD: the circumference direction, DD: the depth direction), (b) EBSDimage and (c) grain size distribution for the topmost $5 \mu \mathrm{m}$ thick layer of the friction surface, (d) EBSD image far away from the friction surface.

As conflicting results have appeared in the literature regarding the effect of WEL on mechanical properties on the wheels [21], [22], it is of some interest to assess the potential affects that WEL formation has on the brake disc. To characterize the hardness variation of the WEL and tempered sorbite, a $0.3 \mathrm{~mm} \times 0.3 \mathrm{~mm}$ region of the friction surface with WEL and the matrix in the depth direction as shown in Fig. 11a were chosen. A microhardness test was conducted on these two regions at an interval of $150 \mu \mathrm{m}$ starting from just below the friction surface. Fig. 12presents the Vickers hardness of the matrix and friction surface. Each data point in Fig. $12 \mathrm{c}$ is the average of five test results. The contour of Vickers hardness is given in Fig. 12a where it can be seen that the hardness distribution is nearly homogeneous within the range of $324 \mathrm{HV} \sim 408 \mathrm{HV}$. For the case of friction surface, the contour of Vickers hardness is shown in Fig. 12b, indicating a pronounced gradient distribution in the depth direction. Fig. 12c presents the comparison of the hardness distribution on the friction surface and matrix. The hardness of the matrix is homogeneous, and that on the friction surface is a gradient. The peak hardness of $590 \mathrm{HV}$ develops at the top surface, and decreases with increasing distance away from the surface until it reaches a minimum value of $332 \mathrm{HV}$ which a little bit larger than that of the matrix. With the increase of the depth, the hardness will meet the value of the matrix. The occurrence of WEL on the friction surface as shown in Fig. 11 caused the gradient hardness distribution on the friction surface. 

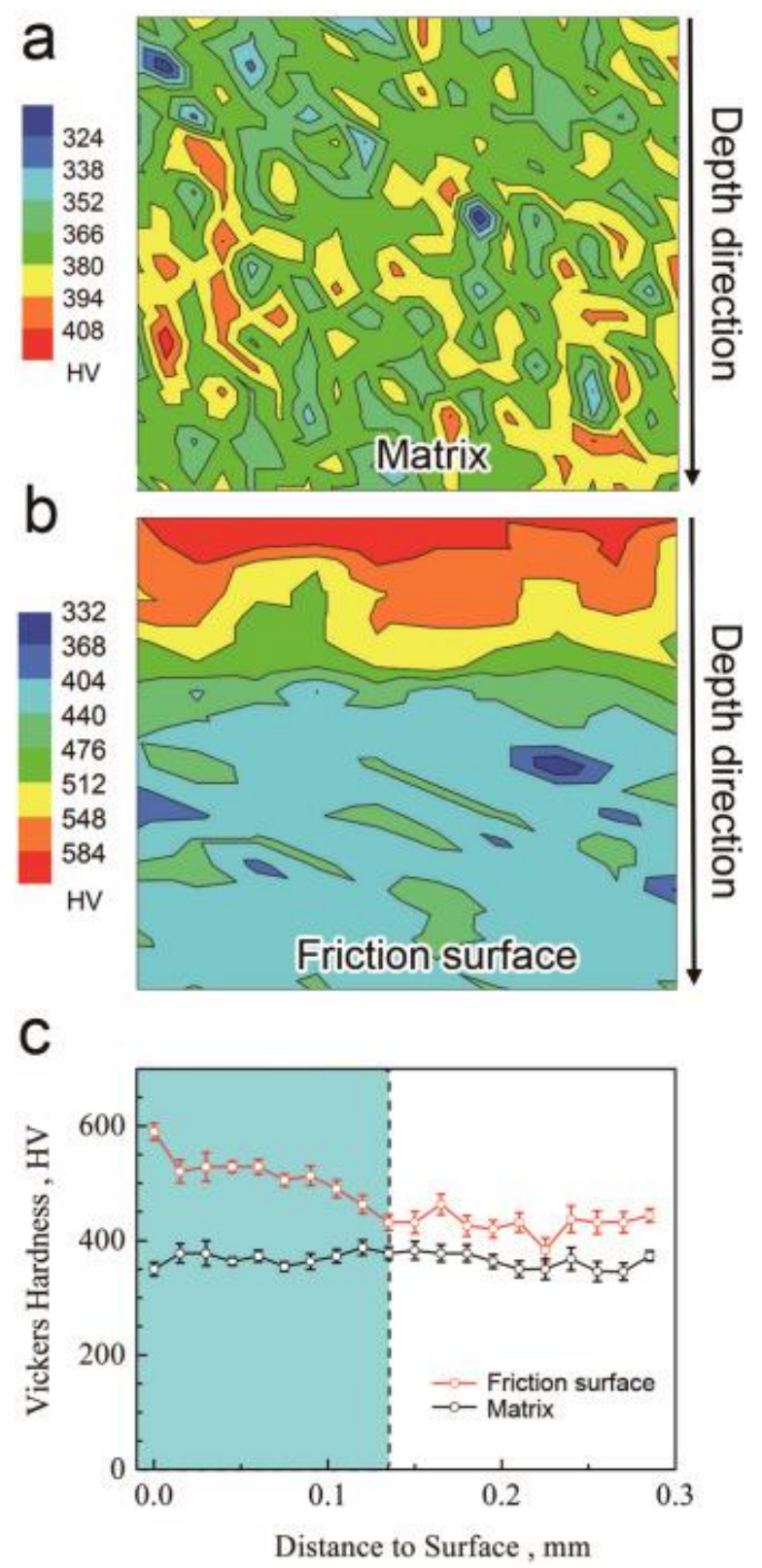

Fig. 12. Vickers hardness of the matrix friction surface, (a) matrix, (b) friction surface with WEL.

Stand-alone gradient layers of various depths from the top surface were also tested to further investigate the mechanical properties of the WEL. Gradient structure in grain size has been reported that can suppress the strain localization and offer a combination of high strength and good ductility [27], [28]. The role of the thickness plays an important role on the mechanical property of the specimens. A specimen with small thickness contains only the deformation microstructure, while that with large thickness consists of deformation microstructure and matrix. Engineering stress-strain curves including the specimens with different thicknesses and matrix are shown in Fig. 13, indicating different yield strength and uniform elongation. The top layer of $0.05 \mathrm{~mm}$ thickness, i.e. $\mathrm{GL}^{0.05} \mathrm{film}$, has the yield strength as high as $1050 \mathrm{MPa}$ but necking occurred soon after yielding. Increasing the thickness to $0.1 \mathrm{~mm}$ and $0.21 \mathrm{~mm}$ ( $\mathrm{GL}^{0.1}$ and $\mathrm{GL}^{0.21}$ films) led to a decrease in yield strength and increase in uniform elongation. Further, with the increase of the thickness to $0.35 \mathrm{~mm}$ and $0.5 \mathrm{~mm}$, the yield strength almost kept the same and the uniform elongation reached to $9 \%$, which are both better than that of coarse grain specimen (CG). The specimens with the thickness of $0.35 \mathrm{~mm}$ and $0.5 \mathrm{~mm}$ contain the WEL 
and matrix which presents both better strength and ductility. This suggests that the WEL improves the tensile properties for the case of a brake disc.

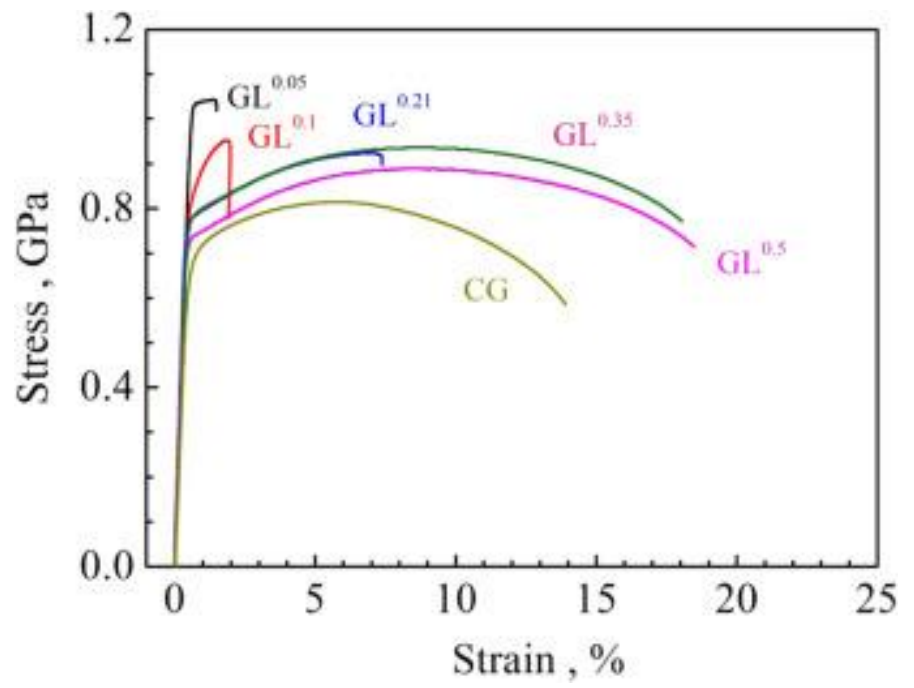

Fig. 13. Engineering stress-strain curves. GL: gradient layer of the friction surface. Superscript: GL thickness (mm). CG: coarse grain layer in the interior.

\subsection{WEL formation}

WEL formation consisted of tempered sorbite transforming to ferrite and significant grain refinement which is attributed to the friction of disc and pads. Two WEL formation mechanisms have been reported in the literature [20] and can be classified as either mechanically-induced or thermally-induced WEL. In general, a thermally-induced WEL presents a sharp transition zone between the WEL and the matrix. The thermally induced WELs have gone through austenitization. The austenite was a result of phase transformation from the original microstructure [29]. However, no sharp transition zone was observed in the WEL and matrix as shown in Fig. 11a. Additionally, no retained austenite was observed when the WEL was analyzed by EBSD in Fig. 11b. Temperature rise is also an important factor for the mechanically-induced or thermally-induced WEL formation, and Fig. 14 shows the results of in-situ thermographic measurements for the friction surface during braking. It can be seen that the maximum temperature achieved on the friction surface during braking was about $440{ }^{\circ} \mathrm{C}$, which is substantially lower than the minimum austenitization temperature of $720^{\circ} \mathrm{C}$. Considering the lack of any discernible boundary between WEL and matrix, the absence of retained austenite in the WEL, and the peak temperatureduring braking being lower than the austenitization temperature, It can be concluded that the mechanically-induced through severe plastic deformation mechanism is likely responsible for WEL formation mechanism in a brake disc. Severe plastic deformation has been found to be effective in refining grains of polycrystalline metals and alloys [27], [28]. When applying surface severe plastic deformation with high strainrates and high strain gradients, a gradient nano-grained surface layer can form on a coarse grained substrate. Refinement of coarse grains in metals is usually governed by dislocation activities that subdivide the original coarse grains, such as dislocation boundaries, low and high angle grain boundaries. The mechanicallyinduced mechanism of WEL formation in the sliding of disc and pads is similar to the surface mechanical grinding treatment which is used to manufacture gradient structure metals [30], [31]. The WEL was a typical kind of gradient structure, which can produce a combination of high strength and considerable ductility [32], [33]. 

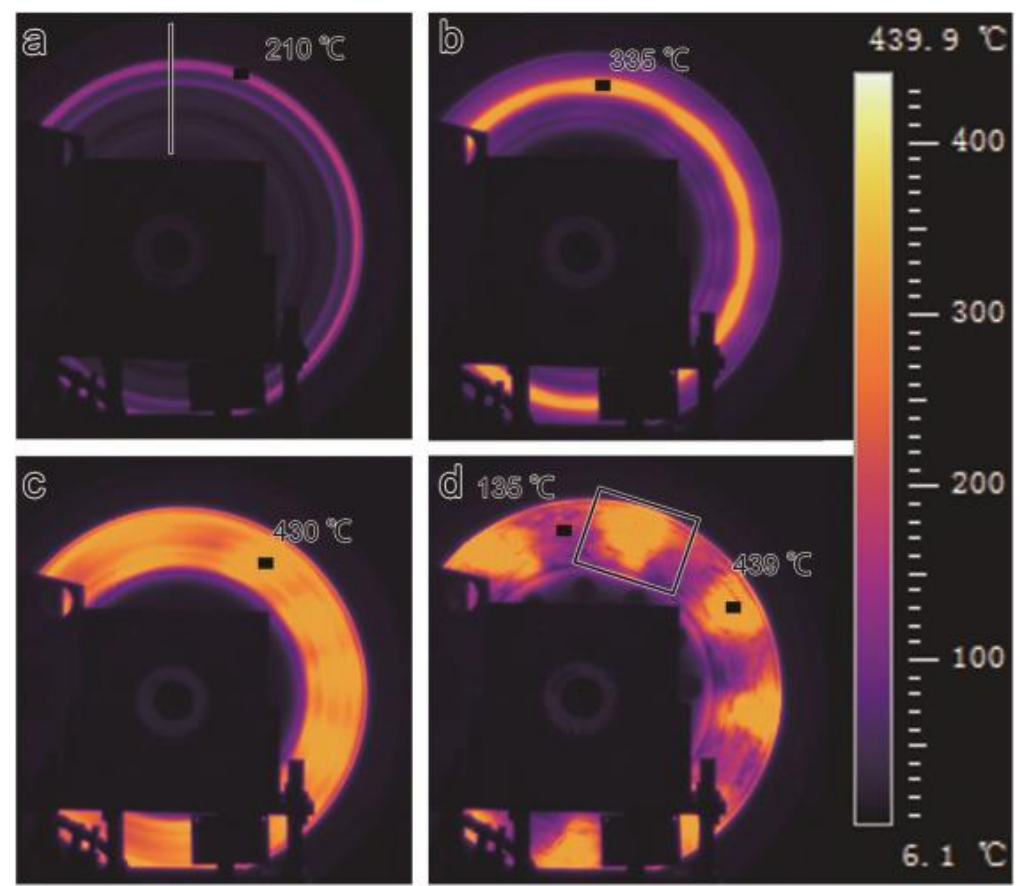

Fig. 14. In-situ thermographic measurements showing temperature distribution on the friction surface for braking time of (a) $1 \mathrm{~s},(\mathrm{~b}) 3 \mathrm{~s}$, (c) $9 \mathrm{~s}$, and (d) $135 \mathrm{~s}$.

\section{Conclusions}

In this paper, fatigue crack propagation and microstructural transformation on the friction surface of a highspeed railway brake discwere analyzed. A full-scale test bench was used to simulate a series of braking cycles, after which mechanical testing and metallographic observation were performed. Based on the results obtained, the following conclusions can be drawn.

1) Heat checking and radial main crack were observed on the friction surface of a high-speed railway brake disc. Only scrape marks appeared on the friction surface in the first one thousand braking cycles. Heat checking initiated during the next $10^{3}-10^{4}$ braking cycles. After $10^{4}$ times braking cycles, radial main cracks began to appear.

2) A crack initiation and propagation mechanism was proposed, i.e., (i) occurrence of heat checking caused by heating and cooling transients during braking; (ii) heat checking increasing the roughness of the friction surface which in turn caused local stress concentration and (iii) localized friction stress and thermal stress driving the heat checking to propagate and coalesce with the radial main crack.

3) WEL within nanosized ferrite formed on the friction surface of railway brake disc, which caused a gradient hardness distribution in the depth direction. The occurrence of WEL can also improve the mechanical properties of brake disc.

4) Considering the inexistence of an evident boundary between WEL and matrix, the absence of austenite in the WEL, and the peak temperature during braking being lower than the austenitization temperature, the formation of the WEL is attributed to the mechanically surface severe plastic deformation caused by the friction between the disc and pad during braking. 


\section{Acknowledgements}

The National Natural Science Foundation of China (No. 11802011), the Joint Funds of the National Natural Science Foundation of China (No. U1834202), the Fundamental Research Funds for the Central Universities(No. 2017RC028 and 2017JBM052), the National Key R\&D Program of China (No. 2017YFB1201302), and the National Key Technology R\&D Program (No. 2015CB654805) are gratefully acknowledged.

\section{References}

[1] J. Bijwe, Composites as friction materials: recent developments in non-asbestos fiber reinforced friction materials-a review. Polym. Compos., 18 (1997), pp. 378-396

[2] J. Campos, G. De Rus, Some stylized facts about high-speed rail: a review of HSR experiences around the world. Transp. Policy, 16 (2009), pp. 19-28

[3] A. Ekberg, B. Akesson, E. Kabo, Wheel/rail rolling contact fatigue-probe, predict, prevent. Wear, 314 (2014), pp. 2-12

[4] M. Givoni, Development and impact of the modern high-speed train: a review. Transp. Rev., 26 (2006), pp. 593-611

[5] F.C. Zhang, B. Lv, C.L. Zheng, Q. Zou, M. Zhang, M. Li, T.S. Wang, Microstructure of the worn surfaces of a bainitic steel railway crossing. Wear, 268 (2010), pp. 1243-1249

[6] H.W. Zhang, S. Ohsaki, S. Mitao, M. Ohnuma, K. Hono, Microstructural investigation of white etching layer on pearlite steel rail. Mater. Sci. Eng. A, 421 (2006), pp. 191-199

[7] Z. Li, J. Han, Z. Yang, L. Pan, The effect of braking energy on the fatigue crack propagation in railway brake discs. Eng. Fail. Anal., 44 (2014), pp. 272-284

[8] P. Dufrénoy, D. Weichert, A thermomechanical model for the analysis of disc brake fracture mechanisms. J. Therm. Stress., 26 (2003), pp. 815-828

[9] G.A. Qian, W.S. Lei, M. Niffenegger, V.F. Gonzalez, On the temperature independence of statistical model parameters for cleavage fracture in ferritic steels. Philos. Mag., 98 (2018), pp. 959-1004

[10] D.J. Kim, Y.M. Lee, J.S. Park, C.S. Seok, Thermal stress analysis for a disk brake of railway vehicles with consideration of the pressure distribution on a frictional surface. Mater. Sci. Eng.: A, 483 (2008), pp. 456-459

[11] Z. Yang, J. Han, W. Li, Z. Li, L. Pan, X. Shi, Analyzing the mechanisms of fatigue crack initiation and propagation in CRH EMU brake discs. Eng. Fail. Anal., 34 (2013), pp. 121-128

[12] S.C. Wu, S.Q. Zhang, Z.W. Xu, Thermal crack growth-based fatigue life prediction due to braking for a highspeed railway brake disc. Int. J. Fatigue, 87 (2016), pp. 359-369

[13] Guian Qian, Y. Cao, M. Niffenegger, Yuh J. Chao, W. Wu, Comparison of constraint analyses with global and local approaches under uniaxial and biaxial loadings. Eur. J. Mech. A-Solids (69) (2018), pp. 135-146

[14] A. Ekberg, E. Kabo, Fatigue of railway wheels and rails under rolling contact and thermal loading-an overview. Wear, 258 (7-8) (2005), pp. 1288-1300

[15] S.X. Li, Y.S. Su, X.D. Shu, J.J. Chen, Microstructural evolution in bearing steel under rolling contact fatigue. Wear, 380-381 (2017), pp. 146-153

[16] S.B. Newcomb, W.M. Stobbs, A transmission electron microscopy study of the white-etching layer on a rail head. Mater. Sci. Eng., 66 (1984), pp. 195-204

[17] L.B. Wan, S.X. Li, S.Y. Lu, Y.S. Su, X.D. Shu, H.B. Huang, Case study: formation of white etching layers in a failed rolling element bearing race. Wear, 396-397 (2017), pp. 126-134

[18] W. Lojkowski, M. Djahanbakhsh, G. Bürkle, S. Gierlotka, W. Zielinski, H.J.Fecht, Nanostructure formation on the surface of railway tracks. Mater. Sci. Eng. A, 303 (2001), pp. 197-208

[19] W. Österle, H. Rooch, A. Pyzalla, L. Wang, Investigation of white etching layers on rails by optical microscopy, electron microscopy, X-ray and synchrotron X-ray diffraction. Mater. Sci. Eng. A, 303 (2001), pp. 150-157

[20] S.B. Hosseini, U. Klement, Y. Yao, K. Ryttberg, Formation mechanisms of white layers induced by hard turning of AISI 52100 steel. Acta Mater., 89 (2015), pp. 258-267 
[21] Y.B. Guo, A.W. Warren, F. Hashimoto, The basic relationships between residual stress, white layer, and fatigue life of hard turned and ground surfaces in rolling contact. CIRP J. Manuf. Sci. Technol., 2 (2010), pp. 129-134

[22] S. Smith, S.N. Melkote, E. Lara-Curzio, T.R. Watkins, L. Allard, L. Riester, Effect of surface integrity of hard turned AISI 52100 steel on fatigue performance. Mater. Sci. Eng. A, 459 (2007), pp. 337-346

[23] C.D. Cho, H.J. Cho, A study of thermal and mechanical behaviour for the optimal design of automotive disc brakes, Proceedings of the institution of Mechanical Engineers. Proc. Inst. Mech. Eng. Part D: J. Automob. Eng., 222 (2008), pp. 895-915

[24] A.L. Cristol-Bulthé, Y. Desplanques, G. Degallaix, Coupling between friction physical mechanisms and transient thermal phenomena involved in pad-disc contact during railway braking. Wear, 263 (2007), pp. $1230-1242$

[25] B.C. Goo, C.H. Lim, Thermal fatigue evaluation of cast iron discs for railway vehicles. Procedia Eng., 2 (2010), pp. 679-685

[26] B.C. Goo, C.H. Lim, Thermal fatigue of cast iron brake disk materials. J. Mech. Sci. Technol., 26 (2012), pp. 1719-1724

[27] X.L. Wu, P. Jiang, L. Chen, F. Yuan, Y.T. Zhu, Extraordinary strain hardening by gradient structure. Proc. Natl. Acad. Sci. USA, 111 (2014), pp. 7197-7201

[28] X.L. Wu, P. Jiang, L. Chen, J.F. Zhang, F.P. Yuan, Y.T. Zhu, Synergetic Strengthening by Gradient. Struct. Mater. Res. Lett., 2 (2014), pp. 185-191

[29] C. Bernsteiner, G. Müller, A. Meierhofer, K. Six, D. Künstner, P. Dietmaier, Development of white etching layers on rails: simulations and experiments. Wear, 366-367 (2016), pp. 116-122

[30] W.L. Li, N.R. Tao, K. Lu, Fabrication of a gradient nano-micro-structured surface layer on bulk copper by means of a surface mechanical grinding treatment. Scr. Mater., 59 (2008), pp. 546-549

[31] X.C. Liu, H.W. Zhang, K. Lu, Formation of nano-laminated structure in nickel by means of surface mechanical grinding treatment. Acta Mater., 96 (2015), pp. 24-36

[32] M. Yang, Y. Pan, F. Yuan, Y. Zhu, X. Wu, Back stress strengthening and strain hardening in gradient structure. Mater. Res. Lett., 1 (2016), pp. 1-7

[33] M.X. Yang, F.P. Yuan, Q.G. Xie, Y.D. Wang, E. Ma, X.L. Wu, Strain hardening in Fe-16Mn-10Al-0.86C-5Ni high specific strength steel. Acta Mater., 109 (2016), pp. 213-222 